\title{
Ready for a paradigm shift? Part 2: Introducing qualitative research methodologies and methods
}

\author{
Nicola J. Petty, Oliver P. Thomson, Graham Stew
}

Keywords: Qualitative research Methodology Methods

a b s t r a c t

This paper explores a number of commonly used methodologies and methods in qualitative research, namely grounded theory, case study, phenomenology, ethnography and narrative research. For each methodology a brief history of its development and variants is given, followed by typical methods of data collection and analysis. Examples of manual therapy qualitative research studies are highlighted for each methodology. Data collection methods are then discussed and include individual interviews, focus groups, observation and documentary analysis. A frequently used method of data analysis, thematic analysis, is briefly explained. Finally, the strategies to enhance the quality of qualitative research is explored and compared to those of quantitative research.

\section{Introduction}

This is the second of a two-part paper exploring qualitative research within manual therapy. In part one, the types of knowledge used in clinical practice were identified and this led to a discussion of the value of knowledge generated from qualitative research (Petty et al., 2012). It examined the philosophical underpinnings of this type of approach, comparing it to that of quantitative research. Having laid the theoretical and philosophical underpinnings, this second paper explores the various methodologies and methods used in qualitative research. Qualitative research is generally used as a broad umbrella term for a range of research methodologies, with differing epistemological assumptions. As will be seen in the next section, not all qualitative methodologies are underpinned by an interpretivist epistemology.

\section{Methodologies}

Methodology refers to 'the theoretical, political and philosophical backgrounds to social research and their implications for research practice and for the use of particular research methods' (Robson, 2011, p. 528). Methods, on the other hand, refers to techniques used to acquire and analyse data to create knowledge. Methodology is thus a strategy of enquiry that guides a set of procedures (Denzin and Lincoln, 2000; Creswell, 2009). There is a broad range of methodologies as seen in Table 1. This paper will discuss the five most commonly used methodologies outlined in Table 2.

\subsection{Grounded theory}

This methodology was developed by Glaser and Strauss from the University of California in the 1960s (Glaser and Strauss, 1967) and is rooted in sociology. It aims to generate a theory that explains a social process, action or interaction. The theory is constructed or 'grounded' from the data of participants who have experienced the phenomenon under study. Since its inception a number of variants have emerged by a number of authors including Bowers, Charmaz, Clarke, Glaser, Strauss, Strauss and Corbin, Schatzman, (for an overview see Morse et al., 2009). While Glaserian grounded theory follows a more positivist approach with the emergence of concepts from the data, others follow an interpretivist approach to grounded theory whereby theory is constructed by the researcher (e.g. Charmaz, 2006). Most commonly data collection involves interviews, although observation and documentary data may also be used.

The method of data analysis involves coding data (such as interview transcripts), by allocating labels to events, actions and approaches. As data analysis continues, the researcher abstracts these codes into broader more conceptual concepts and categories to capture the complexities of the social process. This process is facilitated by constantly comparing similarities and differences within and between the data set; a process referred to as the 
Table 1

Types of methodologies.

\section{Case study}

Grounded theory

Ethnography

Phenomenology

Narrative

Evaluation research

Action research and participatory action research

Hermeneutics

Feminism

constant comparative method of analysis. Data collection and data analysis occur concurrently, taking an iterative process. Purposeful sampling is initially used but then sampling is based on theoretical relevance to the developing theory, a process known as theoretical sampling; this continues until there is theoretical saturation or sufficiency. Throughout, the researcher documents ideas and hypotheses as theoretical memos that help to build relationships between codes that facilitate the identification of the conditions, action/interactions and consequences of the social process under investigation. Relationships between abstracted codes are identified to create an explanatory matrix or model and the writing up of this constitutes a substantive theory.

This qualitative methodology may be well known to readers familiar with the seminal work of Gail Jensen and colleagues (1999, 2000) describing the nature of expertise amongst physical therapists and of Ian Edwards et al. (2004) on clinical reasoning strategies in physical therapy. Both used a grounded theory case study approach within the interpretivist paradigm.

\subsection{Case study}

This methodology originates from human and social sciences as well as evaluative research (Creswell, 2007). It is the science of the singular (Simons, 1980; Bassey, 1999); it aims to understand what is distinctive of a case defined as 'specific, a complex functioning thing' (Stake, 1995), whether it be a person, a clinic, a classroom, an institution, a programme, a policy, a process or a system (Simons, 2009).

A variety of data may be collected to help deepen understanding of the case and in qualitative studies this commonly includes interview, observation and document analysis. No particular method of data analysis is associated with case study methodology; the researcher is able to choose from a broad range of methods and will be guided by the focus of the case study and research question.

A range of terms are used to describe different types of case studies and include: storytelling and picture drawing, theory seeking and theory testing (Bassey, 1999); intrinsic and instrumental (Stake, 1995); theory-led, theory-generated, evaluation and ethnographic (Simons, 2009); descriptive, exploratory and

Table 2

Five commonly used methodologies and their variants.

\begin{tabular}{lll}
\hline Methodology & Positivist/Postpositivist & Interpretivist \\
\hline $\begin{array}{l}\text { Case study } \\
\text { Grounded } \\
\text { theory (GT) }\end{array}$ & $\begin{array}{l}\text { Yin (2009) } \\
\text { Glaser and Strauss (1967) }\end{array}$ & $\begin{array}{l}\text { Stake (1995) } \\
\text { Strauss and Corbin (1998) } \\
\text { Constructivist Charmaz } \\
\text { (2006) }\end{array}$ \\
Ethnography & $\begin{array}{l}\text { Realist ethnography } \\
\text { Pammersley and Atkinson } \\
\text { (1995) }\end{array}$ & $\begin{array}{l}\text { Performance (McCall, 2000) } \\
\text { Transcendental or } \\
\text { psychological } \\
\text { phenomenology } \\
\text { (Moustakis, 1994) } \\
\text { (Elliott, 2005) }\end{array}$ \\
phenomenology \\
Narrative & & (Elliott, 2005) \\
\hline
\end{tabular}

explanatory (Yin, 2009). Yin (2009) in addition refers to single and multiple-case study design either of which may have a single or multiple unit of analysis. Case study described by Yin follows a more positivist epistemology, while the others (Stake, 1995; Bassey, 1999; Simons, 2009) describe case study from an interpretivist perspective.

With reference to the case studies published in Manual Therapy and highlighted in our previous paper, Smart and Doody (2007) used a multiple-case study approach where the case was the musculoskeletal physiotherapists and the units of analysis were the therapists clinical reasoning processes. Data analysis was guided by the approach described by Miles and Huberman (1994) with identification of codes, themes and categories leading to within-case analysis and finally cross case analysis. In contrast Petty et al. (2011) used a single theory seeking case study as described by Bassey (1999) where the case was the learning transition of individual practitioners embedded within one university programme. The method of data analysis in this study followed a grounded theory approach.

\subsection{Phenomenology}

This methodology originated from Germany at the start of the 20th century and has its roots in psychology and philosophy; hence its association with philosophers such as Heidegger, Gadamer, Satre, Husserl and Merleau-Ponty. In the last 10 years there has been a rapid growth in its use across the world leading to the development of The Organisation of Phenomenological Organisations (http://www.o-p-o.net/).

The focus of this methodology is on understanding the unique lived experience of individuals by exploring the meaning of a phenomenon. From this descriptive data, further interpretation and analysis enables the researcher to uncover a description of the 'essence' of the phenomenon; the universal meaning for individuals. To derive the essence, the researcher puts to one side their own views of the phenomenon, referred to as bracketing, in order to deepen their understanding. The assumption that the researcher can separate themselves in this way has echoes of objectivity within postpositivism. Since language is the medium by which we experience and make meaning of the world, phenomenology is often closely associated with hermeneutics (the science of interpretation and explanation). Given the focus of this methodology, data collection will most often involve individual interviews.

There are two main variants: hermeneutical phenomenology (van Manen, 1990) that assumes the findings are not pure description but rather the interpretation of the researcher, and transcendental phenomenology (Moustakis, 1994) that requires the researcher to bracket out their own views in order to develop a description of what and how they experienced the phenomena. The former variant has been developed as Interpretative Phenomenological Analysis (Smith et al. 2009).

As an example, Osborn and Smith (1998) used phenomenology to explore the personal experience of women with chronic low back pain. Data collection involved individual interviews with nine participants. Findings identified four themes: seeking an explanation, comparing this self with other selves, not being believed and withdrawing from others. Understanding the impact of chronic low back pain on people's lives underpins patient-centred care by health professionals.

\subsection{Ethnography}

This methodology came from comparative cultural anthropology in the early 20th century. By the 1920s and 1930s sociologists from the University of Chicago applied the principles of ethnography to cultural groups in the United States. 
The focus of this methodology is to examine the shared patterns of behaviour, beliefs and language within a cultural group and to do this requires extended times of observation by the researcher. This is most often through participant observation whereby the researcher lives alongside those within the culture, observing and interviewing to develop understanding. A variety of data may be collected to help inform the description of the culture-sharing group, which is then analysed and interpreted (Wolcott, 1994). The researcher thus describes and interprets the meaning of behaviour, language, and interaction amongst the group (Creswell, 2007).

There are a number of variations within ethnography, such as life history, autoethnography and feminist ethnography with two more commonly used approaches being realist ethnography and critical ethnography. Realist ethnography follows a postpositivist tradition of seeking objective knowledge. The researcher observes the culture in a detached and value free way and writes up the 'facts' of the culture in the third person. Participants in the study are not invited to influence the findings; that remains the remit of the researcher. Critical ethnography, emerged in the 1990s, and seeks to emancipate groups of people marginalized in society, by speaking out against inequality, prejudice and domination. Further exploration of ethnography can be found in Atkinson et al. (2007) and Hammersley and Atkinson (2007).

An ethnographic study was used to explore physiotherapists' perceptions of how different types of interactions with patients on a chronic pain unit influenced the achievement of their patients' goals (Thomson, 2008). Data included observation of therapists with patients and follow-up interviews.

\subsection{Narrative research}

This methodology comes from the humanities and social sciences and can follow a qualitative or quantitative approach (Elliott, 2005). It is focused on the detailed stories or life experiences of a single event or a series of events for a small number of individuals (Creswell, 2007). Narrative research may be biographical following the life of individuals, while an oral history explores the personal reflection of events from one or more individuals. A theoretical lens such as feminism may also be used within this type of research.

A variety of data may be collected including observation, participant diaries and letters, documentation, interviews, artifacts and photographs; these help to provide a detailed contextualized story. Data analysis involves reorganizing the stories into chronological order, identifying key aspects and may include interpretation and thematic analysis. The researcher negotiates the meaning of the stories with participants.

An example of narrative research within physiotherapy is a study exploring students' construction of professional identity taking a gender perspective (Hammond, 2011). A post-structural/ post-modern feminist theoretical perspective was adopted. Data collection methods used biographical narrative interviews and audio-diaries and Foucauldian discourse analysis was used.

There are other methodologies available; the above represents a number of commonly used approaches. In contrast, some studies use a mix of approaches such as grounded theory and ethnography, while others may not use a named approach at all, using instead a generic approach (Lichtman, 2006). Determining the quality of the research in these cases may be problematic.

\section{Methods}

Once a methodology has been identified various methods (or tools) may be selected for data collection and data analysis.

\subsection{Sampling methods}

These include purposive, theoretical, convenience and snowball and a brief summary of each is given in Table 3. A frequently used method is purposive sampling that seeks out 'information-rich cases' (Johnson and Waterfield, 2004, p. 124); the researcher may also purposively seek out variation to deepen understanding.

\subsection{Data collection}

A brief description of commonly used data collection methods in qualitative research is offered below. Further exploration of each of these methods can be found in a variety of qualitative textbooks, including Robson (2011).

\subsubsection{Individual interviews}

Interviews are used extensively in qualitative research as a method of data collection. Interviews may be structured, semistructured or unstructured (Robson, 2011). A structured interview will be similar to a questionnaire type approach yielding a fairly superficial level of response. The conduct of semi-structured interviews involves a few pre-determined areas of interest with possible prompts to help guide the conversation. Unstructured interviews involve a broad area to explore and the researcher largely follows the direction of the participant. Interviews can be carried out face to face, by telephone or via the internet. Interviews often take between 30 and $90 \mathrm{~min}$ to complete and are audio-taped for later transcription that can take up to ten times the length of the interview (i.e. a $1 \mathrm{~h}$ interview may take $10 \mathrm{~h}$ for a full transcription). Individual interviews are useful when the researcher wants to explore in-depth the experiences or views of individuals.

\subsubsection{Focus groups}

This method involves a group interview on a particular topic with around $6 \mathrm{e} 10$ individuals, and can be structured, semistructured or unstructured. Depending on the research question, the chosen group may be homogenous or heterogeneous, that is, they may have similar or different experience, background or position. It involves a group discussion facilitated by the researcher and may last between one and $2 \mathrm{~h}$. A second person can help manage any issues that may arise such as someone needing to leave early, take notes of non-verbal communication and supports the researcher in reflecting and debriefing afterwards. The focus group is audio-taped for subsequent transcription. It provides an efficient way to gain a range of rich data, but requires skillful facilitation to manage the dynamics of the group and ensure all voices are heard. Focus groups are useful when the researcher wants to gain a range of views about a particular issue.

\subsubsection{Observation}

Observation may be formal with a schedule of pre-determined areas to notice or informal, whereby the researcher decides while observing what to attend to. In formal observation, the instrument

Table 3

Sampling methods.

\begin{tabular}{ll}
\hline Sampling method & Selection \\
\hline Purposive & $\begin{array}{l}\text { Sample selected according to relevance to study } \\
\text { Sheoretical } \\
\text { and develected on basis of analytical insights }\end{array}$ \\
Convenience & $\begin{array}{l}\text { Sample selected according to ease and convenience } \\
\text { After initially sampling a few participants (purposive } \\
\text { or convenience), participants nominate other } \\
\text { potential participants. }\end{array}$ \\
\hline
\end{tabular}


is the observation schedule or guide, while for informal observation the researcher is the instrument. Furthermore, the researcher may participate in the situation, be part of what is being observed (participant observation) or may take no role in the situation other than that of the observer (non-participant observation). Typically qualitative studies use informal participant observation (Robson, 2011), where data are the interpretations of what is seen by the observer. Data may be captured by a variety of methods including field notes, audio-tape and video-tape; there are issues associated with each of these methods so the choice needs to be carefully considered. While observation enables the researcher to see (and hear) exactly how individuals act and interact in a given situation, the presence of the researcher may influence behaviour. A further issue is that observation is time consuming, with some observation lasting years so that the researcher can be fully immersed in the research field (however, such extended periods of observation are less common in healthcare research). The observer often writes a description of what is observed and then develops a theoretical framework to help explain what is going on in the situation. This leads to a more focused observation of particular issues. One advantage of this method over interview methods is the ability to observe theory-in-action, rather than espoused theory, making it a popular choice for research exploring clinical reasoning and expertise.

\subsubsection{Documentary analysis}

This usually refers to written documents that may take the form of textbooks, articles, notes, minutes of meetings, archives etc. but may also include photographs, drawings, pictures, television programmes etc. In educational research for example, it may be relevant to review the course documentation and timetables. The document may have been created as part of the research study or already in the public domain. Fundamental to analysis of documents is identifying the context of the document, establishing who wrote it and for what purpose (Robson, 2011).

Within any given study a mix of the above data collection methods may be used. For example, a grounded theory study exploring clinical reasoning amongst therapists may initially carryout interviews and later use observation of therapists with patients with a follow up interview with therapists. Using observation methods would enable the researcher to view the theory developed from prior interviews 'in action', and would enable the researcher to further develop the theory and provide an enhanced understanding of the processes being studied. There are other data collection methods that have not been explored and include: verbal protocol (or 'think aloud') that captures thinking within a specific situation; the immediacy offers rich data and has been used to capture the performance of experts in practice; repertory grid techniques; simulation, nominal and interacting groups and Delphi method; critical incident technique, vignettes and visual research methods.

\subsection{Data analysis}

Compared to quantitative research, data analysis in qualitative research can be a very time consuming and laborious process. Typically the researcher continually moves back and forth between data collection and data analysis, that is, it follows an iterative process. The data is most commonly in the form of numerous pages of written words, which then need to be analysed and interpreted. Unfortunately there is no computer programme that will do this; while software such as NVivo (http://www.qsrinternational.com) offer a powerful data management tool, the researcher is still left with data analysis. As in any form of research, planning data analysis needs to occur in the planning stages of a study. The reader working their way through this second paper will perhaps not be surprised to find out that there are a variety of ways to analyse qualitative data. Methods of analysis include: thematic analysis, content analysis, constant comparison method of data analysis, discourse analysis, critical discourse analysis, conversation analysis and analysis of narratives. Further information on data analysis can be found in Gibbs (2007) and Grbich (2007).

A commonly used method is thematic analysis. The researcher initially reads the data several times to gain familiarity with the text as a whole. Codes (labels) are given to sentences, phrases, paragraphs or lines; codes are compared across the whole data set to identify variations, similarities, patterns and relationships; the researcher writes reflections and ideas related to sections of data to abstract from the data and deepen analysis (memo writing); testing out and expanding ideas occurs by collecting further data (by theoretical sampling) that is now more focused; codes are grouped to create a smaller number of themes that distill the key issues identified by the researcher; relationships between themes are then identified to create a thematic map. This process is not a linear sequential process as it appears here; rather analysis involves continual movement across these stages. There are a number of methods for conducting thematic analysis including that of Braun and Clarke (2006).

The findings of qualitative research using grounded theory, phenomenology, narrative and ethnographic methodologies can be conceptualized as having instrumental, symbolic or conceptual use for clinical and policy decision making (Jack, 2006), and is depicted in Fig. 1. Instrumental refers to the direct use of research findings for clinical or policy decisions, for example where barriers to performing exercise are identified. Conceptual refers to research findings that provide insight into an issue, for example understanding the experience of patients attending an exercise class. Symbolic use refers to findings that may validate a service or policy, for example evaluating an existing exercise class.

\section{Quality (or rigour) of qualitative research}

The way in which qualitative research is evaluated is a contentious issue (Sandelowski and Barroso, 2002; Hope and Waterman, 2003; Rolfe, 2006). While some argue for the same criteria as quantitative research (Morse et al., 2002), others argue for different criteria (Sandelowski, 1986; Koch and Harrington, 1998), while still others reject any pre-determined criteria (Hope and Waterman, 2003; Johnson and Waterfield, 2004; Rolfe, 2006). We follow the second view that the different epistemological assumptions of qualitative research require different criteria to that of quantitative research. While it has been argued that each approach requires different criteria (Koch and Harrington, 1998), the commonly accepted criteria that are applied across approaches are summarized Table 4 . Transferability is contingent on credibility, which in turn is contingent on dependability and confirmability (Fig. 2).

Trustworthiness refers to the confidence or trust one can have of a study and its findings (Robson, 2011) and is determined by those assessing a study (c.f. quantitative research that refers to validity which is judged by researcher).

\subsection{Confirmability}

This is the extent to which the findings reflect the focus of the enquiry (Lincoln and Guba, 1985) and not the bias of the researcher (Guba, 1981). The way in which the researcher has made interpretations, implications and conclusions is made explicit through an audit trail. Qualitative, or naturalistic, researchers recognise their own experiences and subjectivity influence their interpretations and this is made known to the reader through a process of reflexivity. Collecting data that provides variation in perspective (triangulation) may also help to reduce researcher bias (Guba, 1981). 


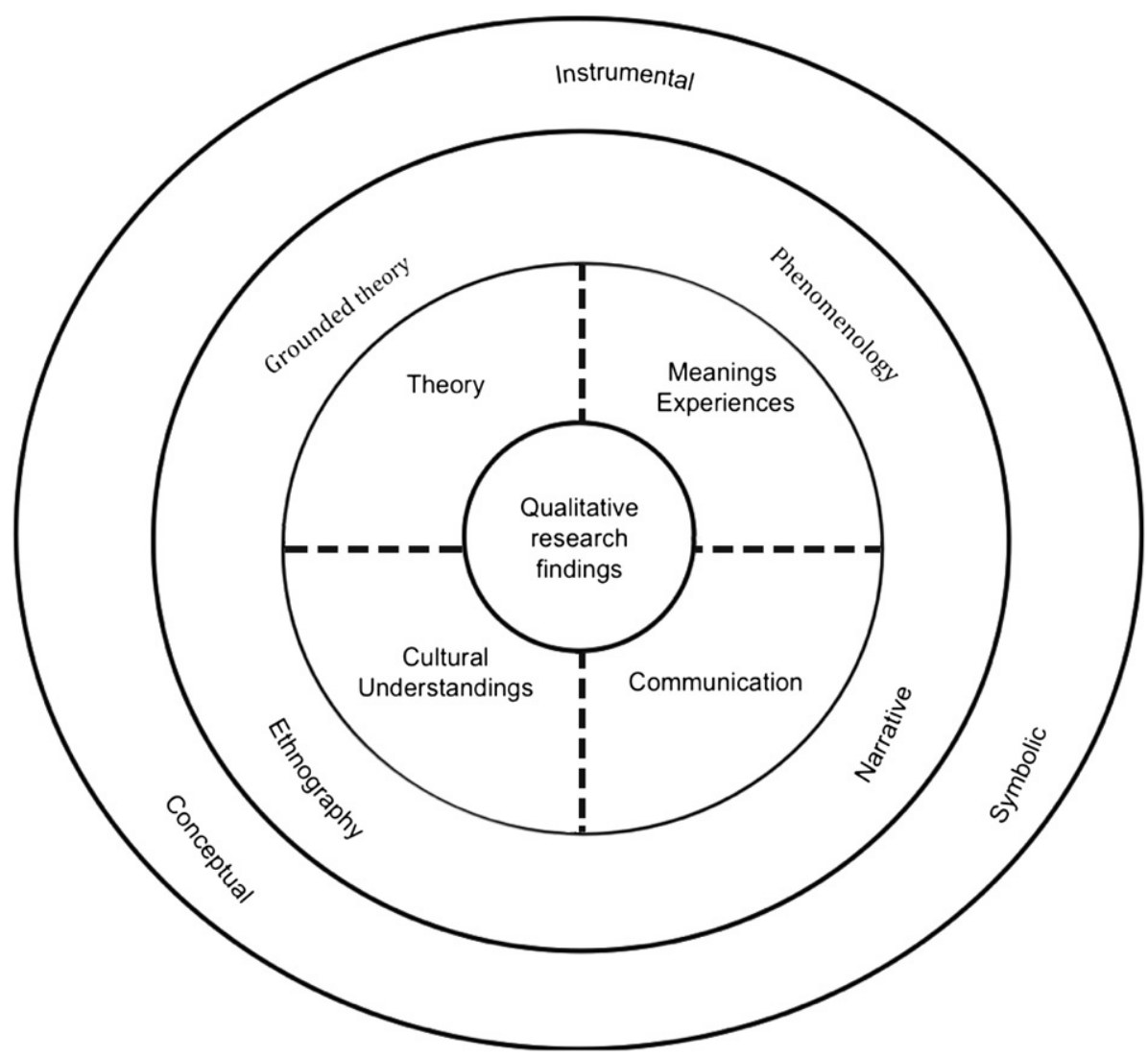

Fig. 1. Framework for using qualitative research findings (after Igo, 2011; with permission).

\subsection{Dependability}

A qualitative study accepts that variations between people and contexts as well as the passage of time will not enable a study to be replicated elsewhere. Furthermore, data analysis is a dynamic and creative activity carried out by the researcher where insights develop and change throughout the process. An audit trail of these procedures and processes carried out by the researcher enable a judgement to be made by another. The audit captures the inevitable change and variation in the researcher's perspective to provide 'trackable variance' (Guba, 1981, p. 81).

\subsection{Credibility}

A qualitative study does not attempt to control the multitude of factors involved in the phenomenon under investigation, it seeks to explore the whole in all its complexity. Interpreting such complexity is challenging for the researcher and a number of strategies are used to facilitate the process (Guba, 1981): prolonged engagement and persistent observation enable researchers to gain a deep understanding of the phenomenon being studied; peer debriefing to test out insights, ideas and analysis with colleagues outside the context; collecting a variety of data from different

Table 4

Criteria for quality in qualitative and quantitative research (Guba and Lincoln, 1981; Lincoln and Guba, 1985; Erlandson, 1993; Nelson, 2008).

\begin{tabular}{|c|c|c|c|}
\hline $\begin{array}{l}\text { Quantitative research } \\
\text { criteria of quality }\end{array}$ & $\begin{array}{l}\text { Qualitative research } \\
\text { criteria of quality }\end{array}$ & Descriptor & Strategies \\
\hline $\begin{array}{c}\text { Objectivity or } \\
\text { neutrality }\end{array}$ & Confirmability & $\begin{array}{l}\text { The extent to which the findings } \\
\text { are the product of the inquiry and } \\
\text { not the bias of the researcher }\end{array}$ & $\begin{array}{l}\text { Audit trail of the process of data analysis } \\
\text { Triangulation } \\
\text { Member checking } \\
\text { Reflexive research journal }\end{array}$ \\
\hline Reliability & $\begin{array}{l}\text { Dependability (consistency, } \\
\text { auditability) }\end{array}$ & $\begin{array}{l}\text { The extent to which the study could } \\
\text { be repeated and variations understood }\end{array}$ & $\begin{array}{l}\text { Audit trail of procedures and processes } \\
\text { Triangulation } \\
\text { Reflexive research journal }\end{array}$ \\
\hline Internal validity & Credibility (truth value) & $\begin{array}{l}\text { The degree to which the findings can } \\
\text { be trusted or believed by the participants } \\
\text { of the study }\end{array}$ & $\begin{array}{l}\text { Prolonged engagement } \\
\text { Persistent observation } \\
\text { Referential adequacy materials } \\
\text { Peer debriefing } \\
\text { Member checking } \\
\text { Triangulation } \\
\text { Negative case analysis } \\
\text { Reflexive research journal }\end{array}$ \\
\hline External validity & $\begin{array}{l}\text { Transferability (applicability, } \\
\text { fittingness) }\end{array}$ & $\begin{array}{l}\text { The extent to which the findings can be } \\
\text { applied in other contexts or with other } \\
\text { participants }\end{array}$ & $\begin{array}{l}\text { Thick description } \\
\text { Purposive sampling } \\
\text { Reflexive research journal }\end{array}$ \\
\hline
\end{tabular}




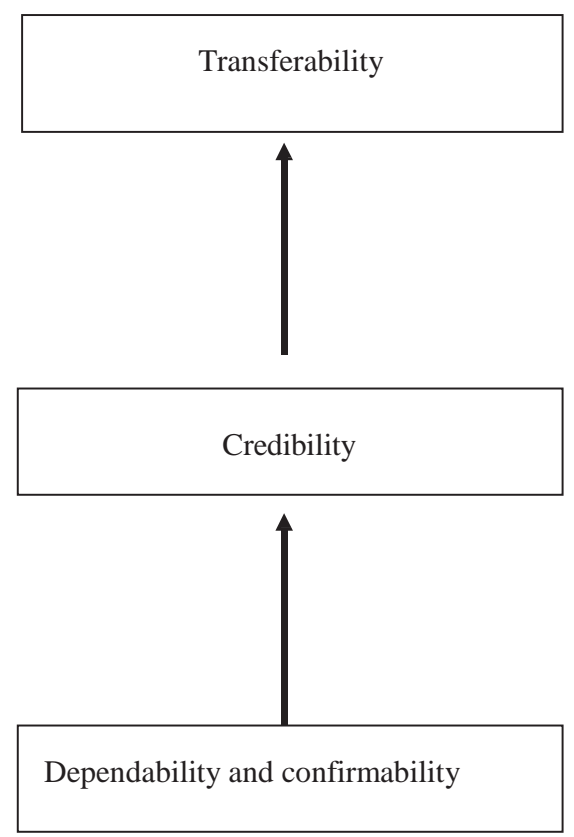

Fig. 2. Hierarchy of criteria for a naturalistic study (Erlandson et al., 1993).

perspectives to cross check interpretations (triangulation); collecting data that enriches understanding of the context such as documents, videotapes, photographs (referential adequacy materials); testing the coherence of the findings, looking for contradictions and considering alternative and competing explanations and negative cases; verifying data and comments on interpretation with study participants (member checking). This last strategy is critical in establishing credibility. To what degree do participants of the study believe the findings; do the findings ring true? To a lesser degree, a study is credible when others external to the study recognize the findings (Sandelowski, 1986).

\subsection{Transferability}

In a qualitative study it is assumed that the findings are context specific and for that reason does not aim to generalize findings. To enhance deep understanding of the phenomenon under investigation, purposive sampling is used to ensure the data provides a range of perspectives. In addition, detailed, thick descriptive data is collected of the phenomenon to enable others to determine the degree to which the findings may be applied to their own setting. This transferability to other settings is also referred to as analytical or theoretical generalization (Robson, 2011). The responsibility for determining transferability is with those who might apply the findings to their own setting (Lincoln and Guba,1985; Sandelowski,1986).

It is worth noting that assessment of the quality of naturalistic research, or indeed quantitative research, with or without socially constructed criteria, is in the end a social judgement (Hammersley, 1990). There is no given external reference point with which to measure against. Furthermore, the strategies described to enhance the rigour of a study do not in themselves guarantee trustworthiness (Robson, 2011).

\section{Summary and conclusions}

This paper has overviewed the commonly used methodologies and methods of data collection and analysis used in qualitative research. The criteria to determine the trustworthiness of a study using this approach has been briefly explored. This paper along with the previous part 1 paper seeks to explain the underlying assumptions, process and procedures of qualitative research to enhance understanding by manual therapists. It is hoped this may trigger more manual therapists to adopt this approach and thereby enhance a more robust and comprehensive knowledge base in manual therapy.

\section{References}

Atkinson P, Coffey A, Delamont S, Lofland J, Lofland L. Handbook of ethnography. London: Sage; 2007.

Atkinson P, Hammersley M. Ethnography: principles in practice. 3rd ed. London: Routledge; 2007.

Bassey M. Case study research in educational settings. Maidenhead: Open University Press; 1999.

Braun V, Clarke V. Using thematic analysis in psychology. Qualitative Research in Psychology 2006;3(2):77e101.

Charmaz K. Constructing grounded theory: a practical guide through qualitative analysis. London: Sage; 2006.

Creswell JW. Qualitative inquiry and research design; choosing among five approaches. Thousand Oaks: Sage; 2007.

Creswell JW. Research design, qualitative, quantitative and mixed methods approaches. 3rd ed. Los Angeles: Sage; 2009.

Denzin NK, Lincoln YS. Handbook of qualitative research. 2nd ed. Thousand Oaks: Sage; 2000.

Edwards I, Jones M, Carr J, Braunack-Mayer A, Jensen GM. Clinical reasoning strategies in physical therapy. Physical Therapy 2004;84(4):312e30.

Elliott J. Using narrative in social research: qualitative and quantitative approaches. London: Sage; 2005.

Erlandson DA, Harris EL, Skipper BL, Allen SD. Doing naturalistic inquiry, a guide to methods. Newbury Park: Sage; 1993.

Gibbs RG. Analyzing qualitative data. Los Angeles: Sage; 2007.

Glaser BG, Strauss AL. The discovery of grounded theory, strategies for qualitative research. New York: Aldine de Gruyter; 1967.

Grbich C. An introduction: qualitative data analysis. London: Sage; 2007.

Guba EG. Criteria for assessing the trustworthiness of naturalistic inquiries. Educational Technology Research and Development 1981;29(2):75e91.

Guba EG, Lincoln YS. Effective evaluation. San Francisco: Jossey-Bass; 1981.

Hammersley M. Reading ethnographic research: a critical guide. London: Longman; 1990

Hammersley M, Atkinson P. Ethnography: principles in practice. London: Routledge; 1995.

Hammond J, Perselli V. Professional identity construction in physiotherapy education e a gender perspective. Physiotherapy 2011;97(Suppl. 1):eS449e50. doi: 10.1016/j.physio.2011.04.002.

Hope KW, Waterman HA. Praiseworthy pragmatism? Validity and action research. Journal of Advanced Nursing 2003;44(2):120e7.

Igo S. Qualitative research evidence: how does it contribute to evidence-based practice? Amsterdam: World Physical Therapy Congress; 2011.

Jack SM. Utility of qualitative research findings in evidence-based public health practice. Public Health Nursing 2006;23(3):277e83.

Jensen GM, Gwyer J, Hack LM, Shepard KF. Expertise in physical therapy practice. Boston: Butterworth Heinemann; 1999.

Jensen GM, Gwyer J, Shepard KF. Expert practice in physical therapy. Physical Therapy 2000;80(1):28e52.

Johnson R, Waterfield J. Making words count: the value of qualitative research. Physiotherapy Research International 2004;9(3):121e31.

Koch T, Harrington A. Reconceptualizing rigour: the case for reflexivity. Journal of Advanced Nursing 1998;28(4):882e90.

Lichtman M. Qualitative research in education, a user's guide. Thousand Oaks: Sage; 2006

Lincoln YS, Guba EG. Naturalistic inquiry. Beverly Hills: Sage; 1985.

McCall MM. Performance ethnography: a brief history and some advice. In: Denzin NK, Lincoln YS, editors. Handbook of qualitative research. 2nd ed. Thousand Oaks: Sage; 2000. p. p421e434. Ch 15.

Miles MB, Huberman AM. Qualitative data analysis, an expanded sourcebook. 2nd ed. Thousand Oaks: Sage; 1994.

Morse JM, Barrett M, Mayan M, Olson K, Spiers J. Verification strategies for establishing reliability and validity in qualitative research. International Journal of Qualitative Methods 2002;1(2):13e22. Retrieved 29.08.11 from, http:// ejournals.library.ualberta.ca/index.php/IJQM/issue/view/384.

Morse JM, Stern PN, Corbin J, Bowers B, Charmaz K, Clarke AE. Developing grounded theory, the second generation. Walnut Creek: Left Coast; 2009.

Moustakis C. Phenomenological research methods. Thousand Oaks: Sage; 1994.

Nelson AM. Addressing the threat of evidence-based practice to qualitative inquiry through increasing attention to quality: a discussion paper. International Journal of Nursing Studies 2008;45:316e22.

Osborn M, Smith JA. The personal experience of chronic benign lower back pain: an interpretive phenomenological analysis. British Journal of Health Psychology 1998;3(1):65e83.

Petty NJ, Scholes J, Ellis L. The impact of a musculoskeletal masters course: developing clinical expertise. Manual Therapy 2011;16(6):590e5. 
Petty NJ, Thomson OP, Stew G. Ready for a paradigm shift? Part 1: Introducing the philosophy of qualitative research. Manual Therapy 2012;17(4): $267 e 74$.

Robson C. Real world research. 3rd ed. Chichester: Wiley; 2011.

Rolfe G. Validity, trustworthiness and rigour: quality and the idea of qualitative research. Journal of Advanced Nursing 2006;53(3):304e10.

Sandelowski M. The problem of rigor in qualitative research. Advances in Nursing Science 1986;8(3):27e37.

Sandelowski M, Barroso J. Reading qualitative studies. International Journal of Qualitative Methods 2002;1(1):74e108. Retrieved 29.08.2011 from, http:// ejournals.library.ualberta.ca/index.php/IJQM/issue/view/385.

Simons H. Towards a science of the singular. Norwich: Centre for Applied Research in Education, University of East Anglia; 1980.

Simons H. Case study research in practice. Los Angeles: Sage; 2009.
Smart K, Doody C. The clinical reasoning of pain by experienced musculoskeletal physiotherapists. Manual Therapy 2007;12:40e9.

Smith JA, Flowers P, Larkin M. Interpretative phenomenological analysis: theory, method and research. London: Sage; 2009.

Stake RE. The art of case study research. Thousand Oaks: Sage; 1995.

Strauss A, Corbin J. Basics of qualitative research. 2nd ed. Thousand Oaks: Sage; 1998

Thomson D. An ethnographic study of physiotherapists' perceptions of their interactions with patients on a chronic pain unit. Physiotherapy Theory and Practice 2008;24(6):408e22.

Van Manen M. Researching lived experience: human science for an action sensitive pedagogy. Albany: State University of New York Press; 1990.

Wolcott HF. Transforming qualitative data, description, analysis, and interpretation. Thousand Oaks: Sage; 1994.

Yin RK. Case study research, design and methods. 4th ed. Los Angeles: Sage; 2009. 